\title{
Adopted Child's Right of Inheritance from the Family of Origin
}

\author{
DOI http://dx.doi.org/10.4314/mlr.v15i2.8
}

Wondewosen Ewunie *

\begin{abstract}
The relationship between adopted child and his/her family of adoption and family of origin is regulated under the Revised Family Code Proclamation No. $213 / 2000$. Accordingly, the adopted child shall retain his/her bond with the family of origin in addition to his/her close relationship with the family of adoption by considering him/her, for all purposes, as the child of the adopter. One of the issues that arises in connection with a child's relationship with his/her family of origin and family of adoption is the right to inheritance. In particular, the issue arises whether the adopted child can inherit his/her family of origin (through intestate succession) while s/he is deemed to be the child of the adopter and bestowed with all rights and duties including inheritance. The assurance of inheritance right to the adopted child from the estate of his/her family of origin depends upon how much the bond with his/her family of origin is maintained. This article focuses on the legal regime with regard to the adopted child's relationship with his/her family of origin with particular emphasis on the adopted child's right to inherit his/her family of origin, in Ethiopia.
\end{abstract}

\section{Key terms}

Inheritance right $\cdot$ Adopted child $\cdot$ Adoptive parents $\cdot$ Natural parents

\section{Suggested citation:}

Wondewosen Ewunie (2021), 'Adopted Child's Right of Inheritance from the Family of Origin' (in Amharic), 15 Mizan Law Review 2: 543-556

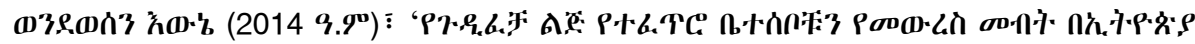

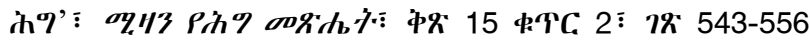

\footnotetext{
* Wondewosen Ewunie, LL.B, LL.M (in Business Law) Addis Ababa University, Prosecutor at Ministry of Justice.

Email: ewuniewondewosen@gmail.com

ORCID: https://orcid.org/0000-0001-9004-0222
} 


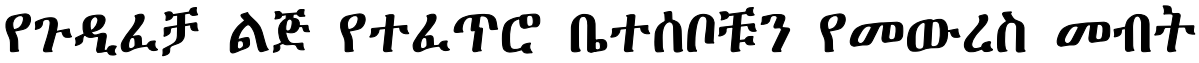

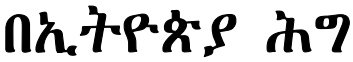

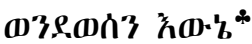

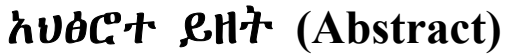

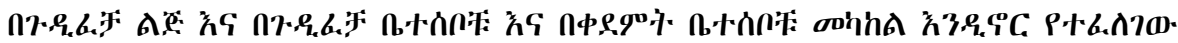

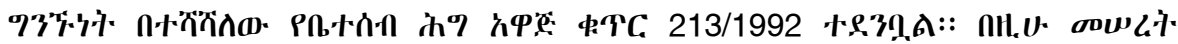

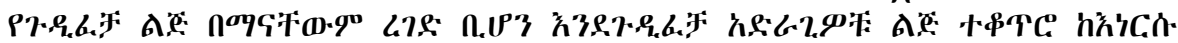

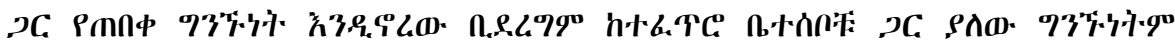

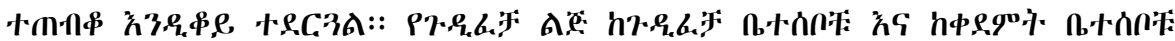
כC hoq,

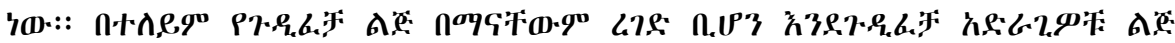

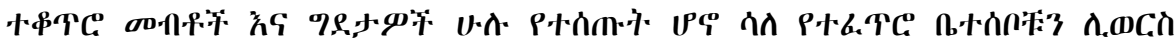

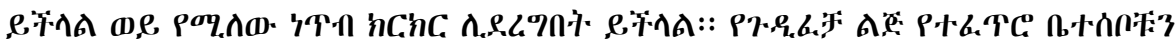

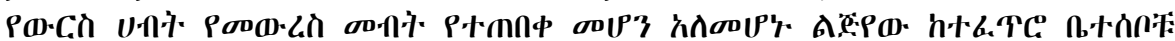

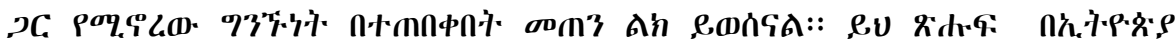

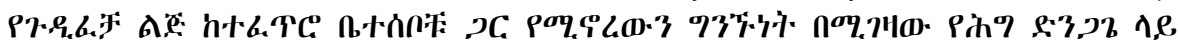

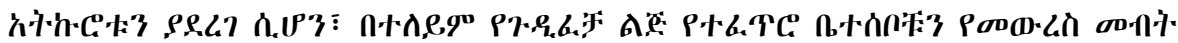

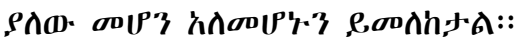

中ดร: фиन:-

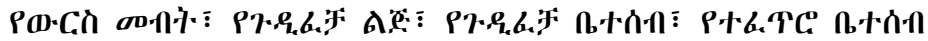

\section{eH'}

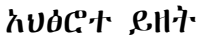

1. $\sigma \mathrm{0} \% \mathrm{\rho}, \rho$

2. P7.

2.1 P7., g.

2.2 P7., G.F A

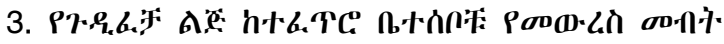

4. $00,9090 \%, \rho$

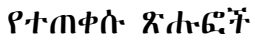

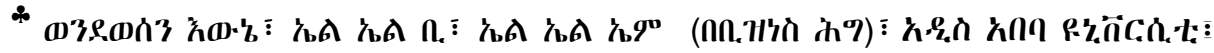

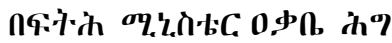

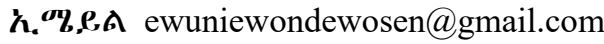

ORCID: https://orcid.org/0000-0001-9004-0222 


\section{1. $00 \% \mathrm{~N}_{\mathrm{s}} \mathrm{P}$}

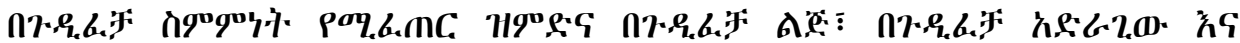

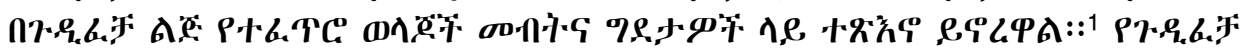

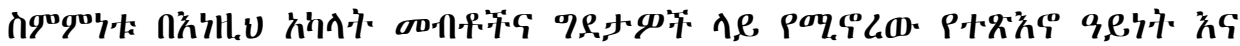

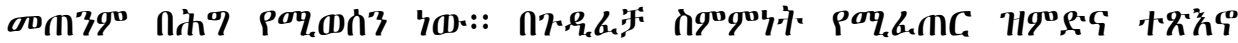
hoq,

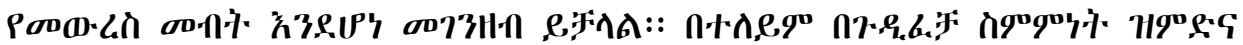

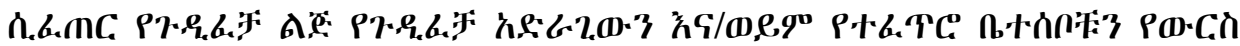

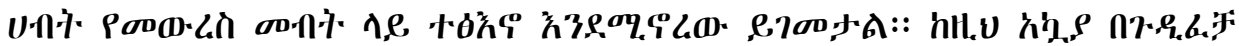

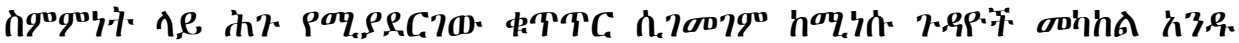

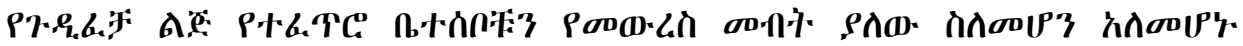

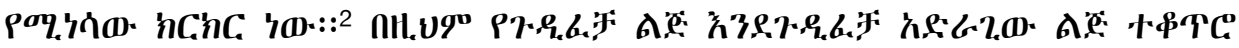

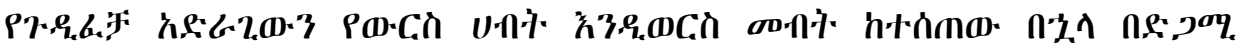

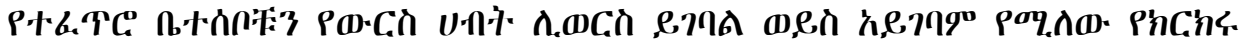

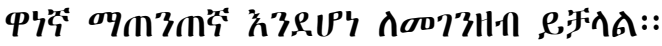

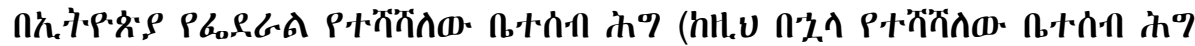

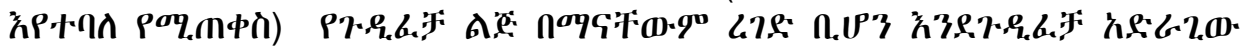

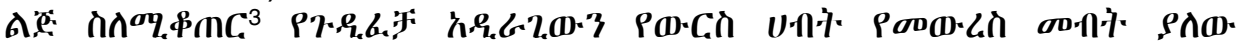
तก

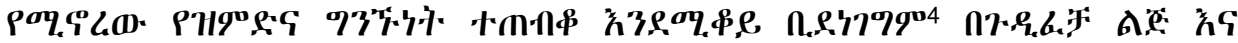

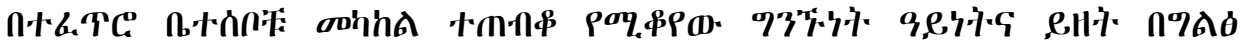

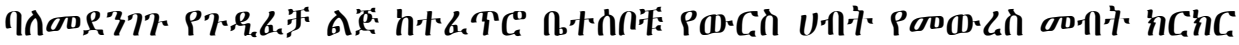

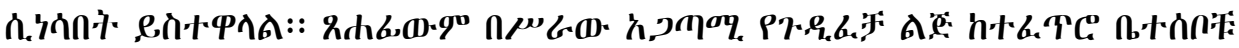

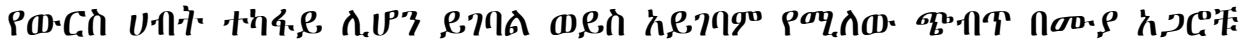

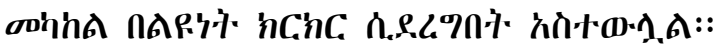

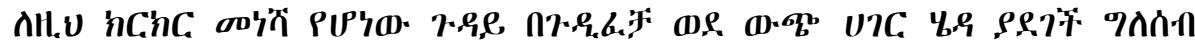
h.t.

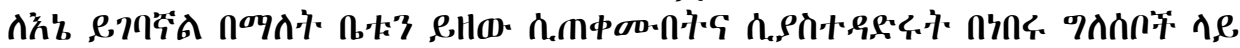

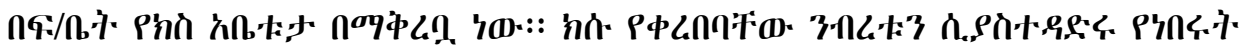

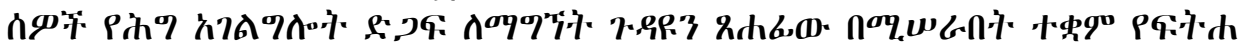

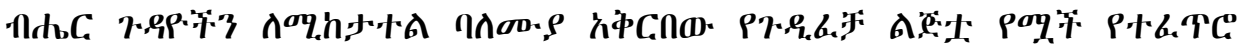

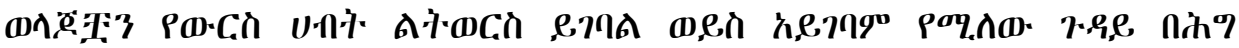

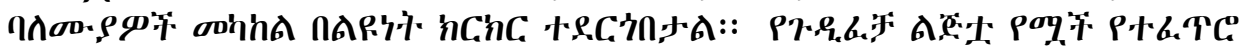

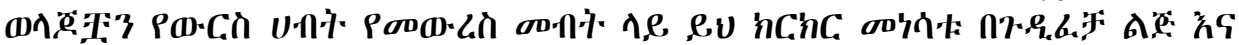

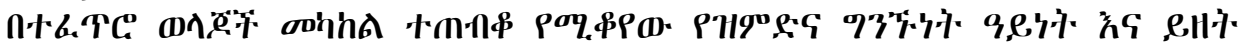

\footnotetext{
${ }^{1}$ Paul A Kiefer (1966), 'Intestate Succession, Sociology and the Adopted Child' 11(2) Vill L Rev 392

2 Donald E Bjertness (1957), 'Domestic Relations - Inheritance by Adopted Children Right of Adopted Child to Inherit from Its Natural Parent' 33(2) N.D. L. Rev. 241 243

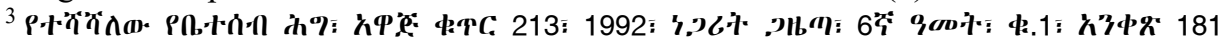

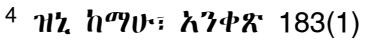




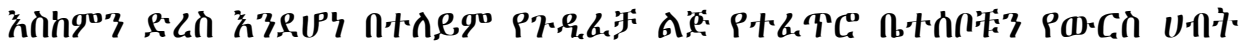

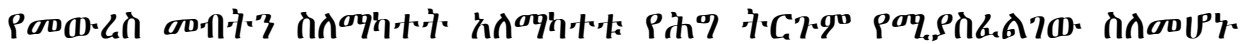

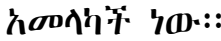

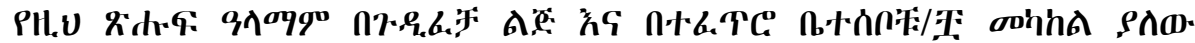

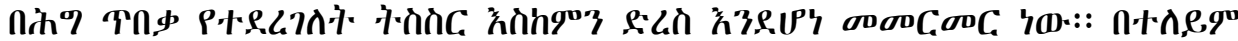

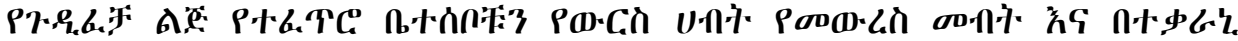

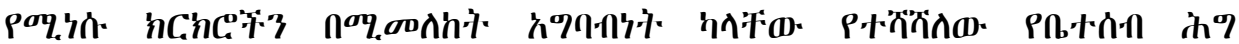

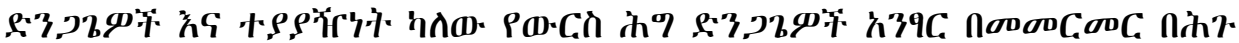

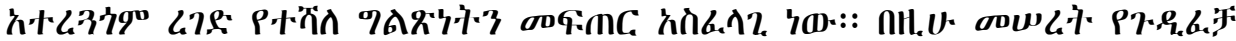

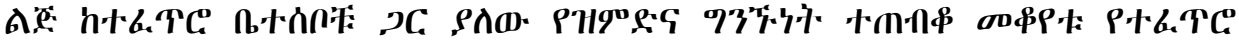

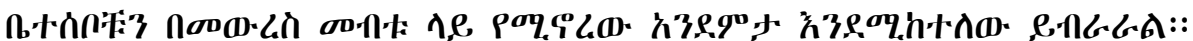

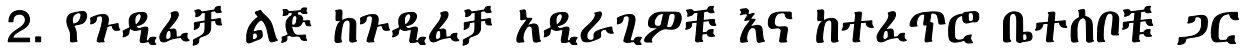

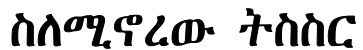

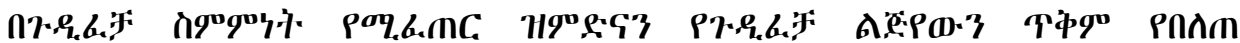

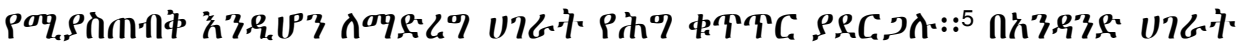

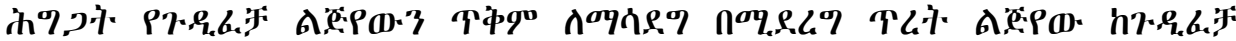
h.

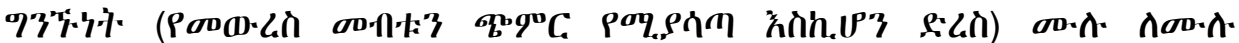

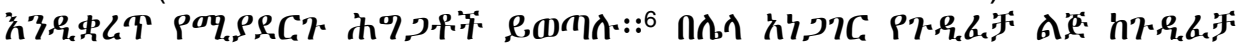

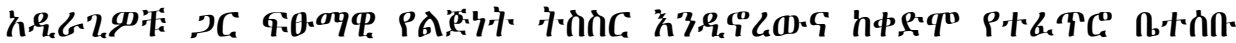

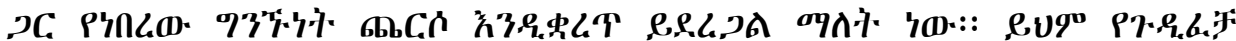

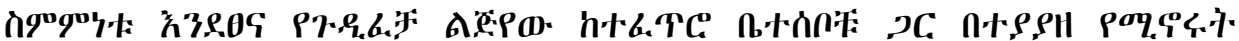

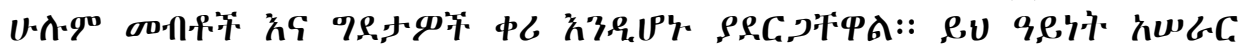

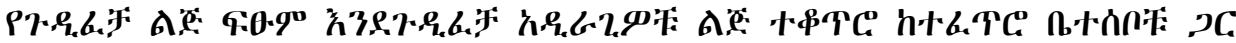

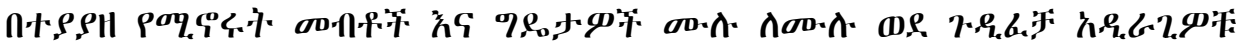

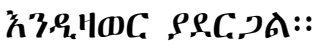

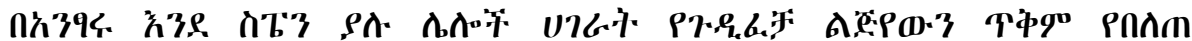

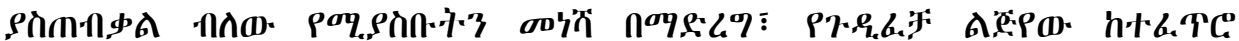

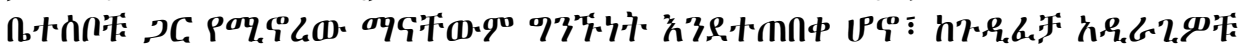

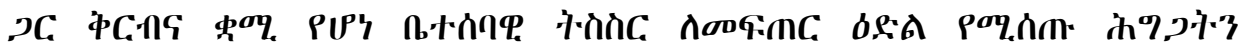

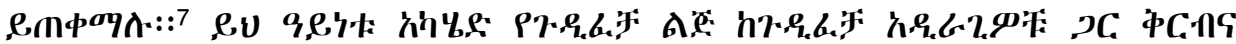

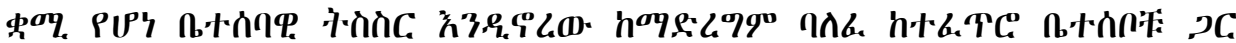

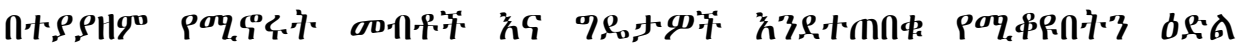

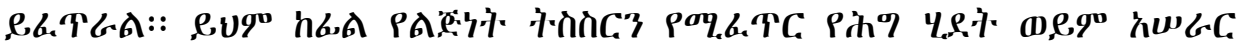

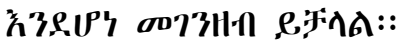

\footnotetext{
${ }^{5}$ Paul A Kiefer, Supra note 1 pp. 393-394

6 John R Jr Murphy (1957), 'Adopted Child's Right of Inheritance from the Natural Parents' 6 Clev-Marshall L Rev 148

${ }^{7}$ Arthur R Thompson (1917), 'Right of the Adopted Child in Intestate Succession' 3(2) ABA $J 135$
} 


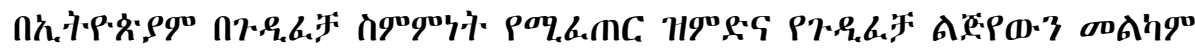

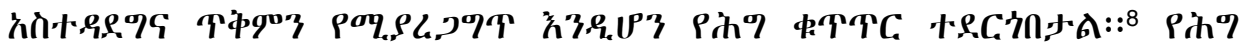

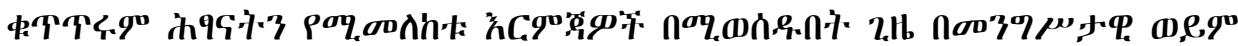

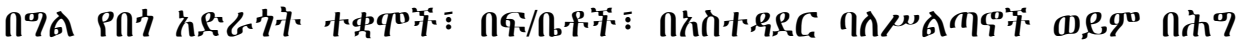

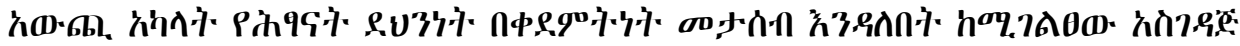

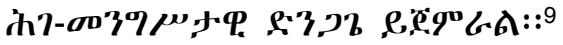

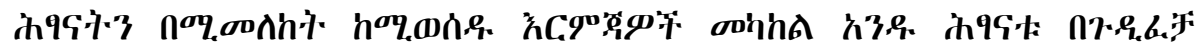

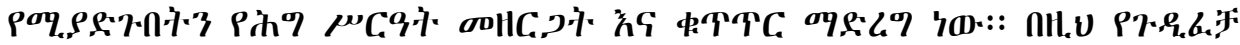

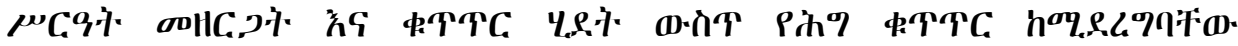
U.b.中.

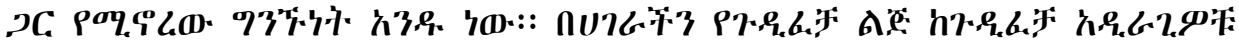

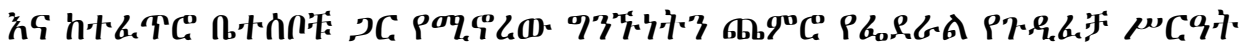

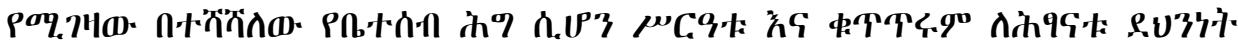

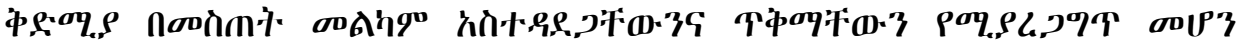

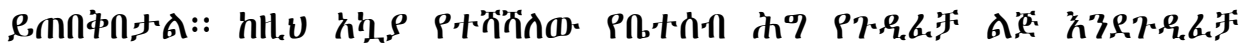
h.

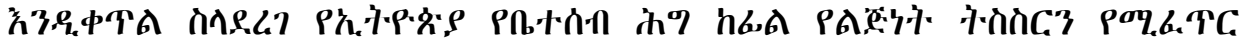

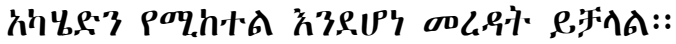

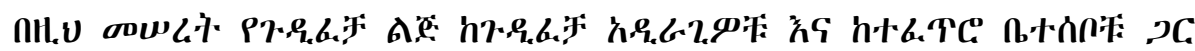

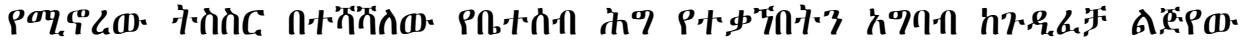

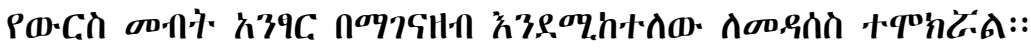

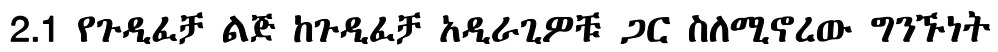

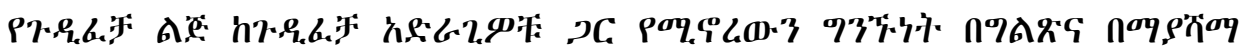

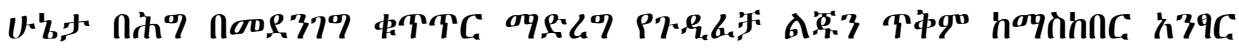

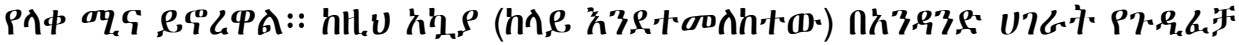

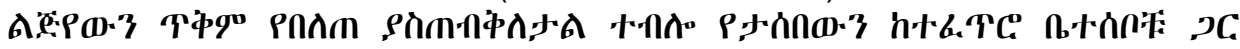

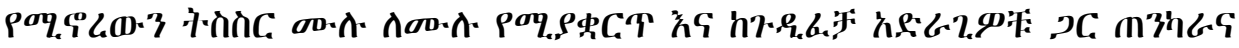

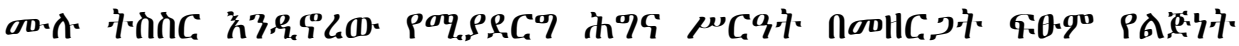

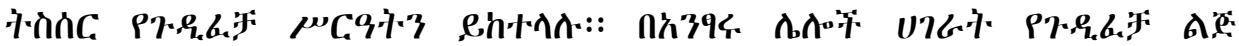

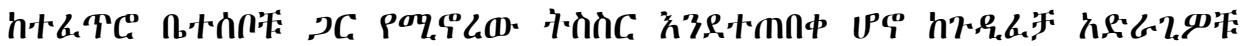

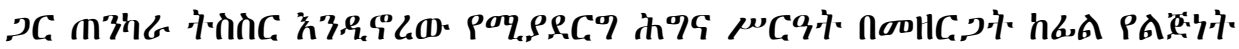

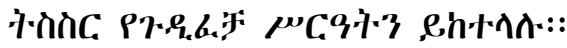

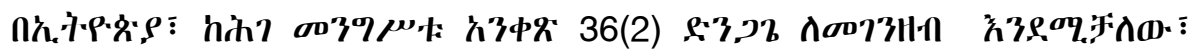

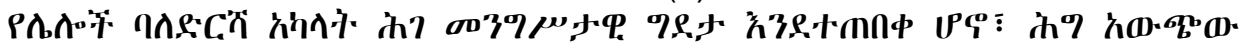

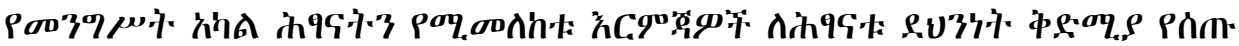

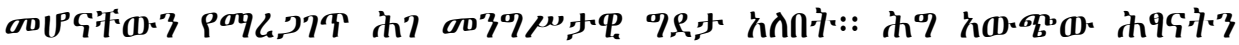

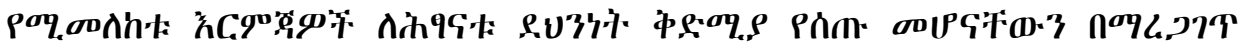

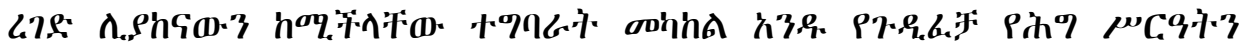

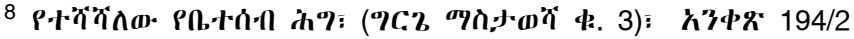

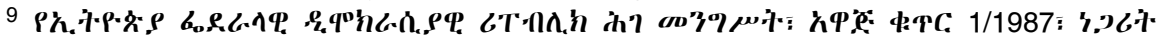

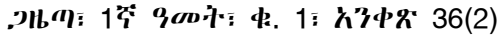




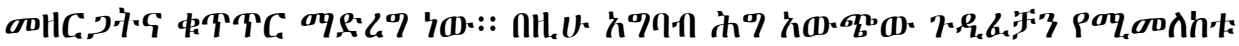

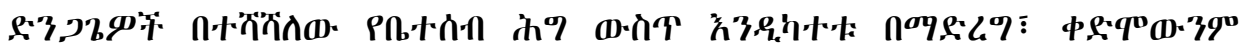
nUרG.

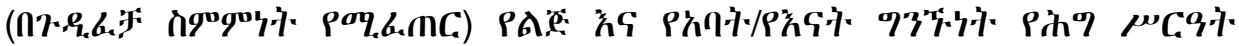

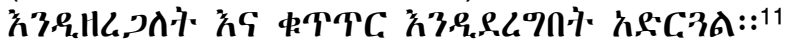

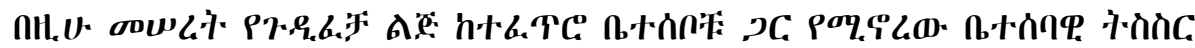

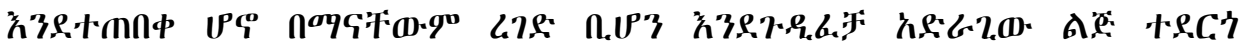

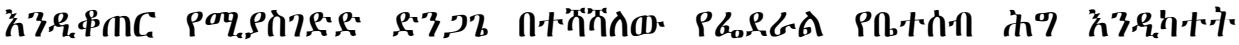

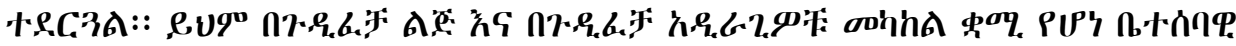

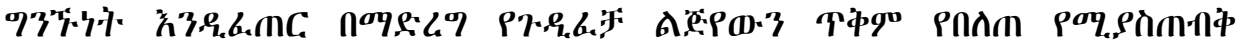

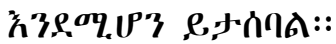

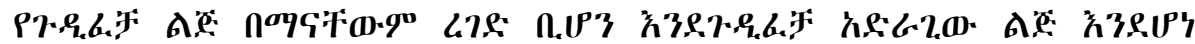

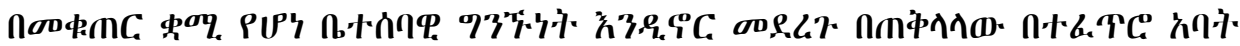

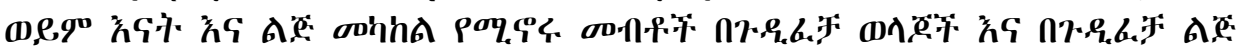

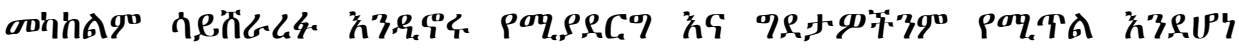
nooL.

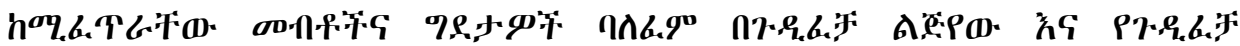

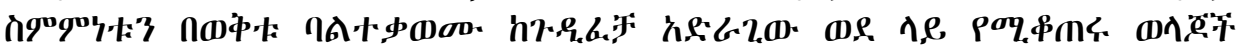

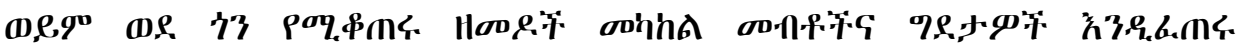
P.C.TA:: 12

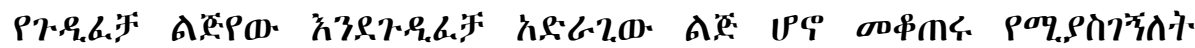

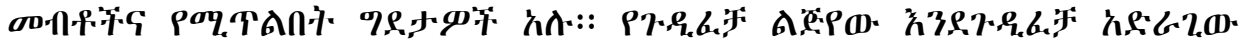

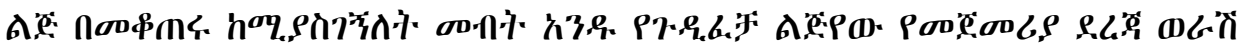

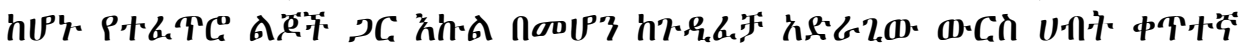

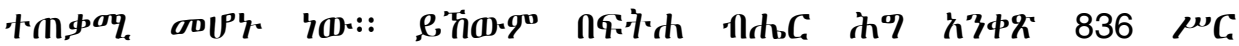

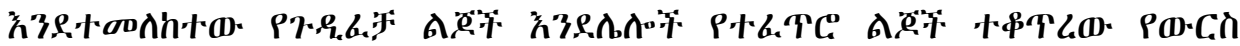

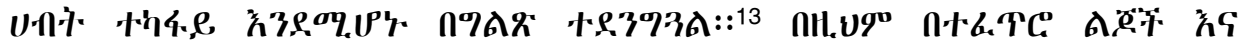
n7.

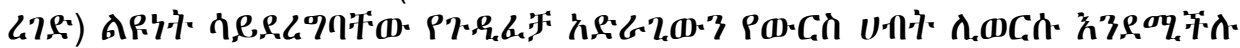
กั073ีก ,

P7.

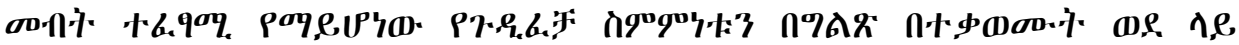

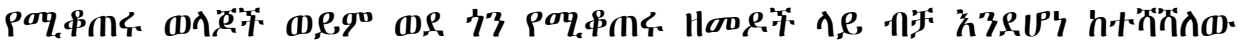

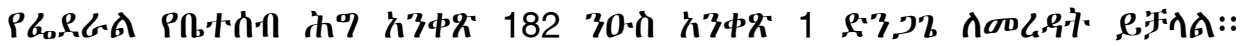

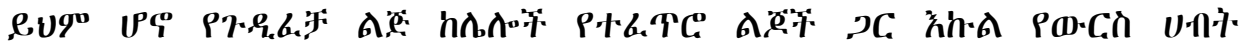

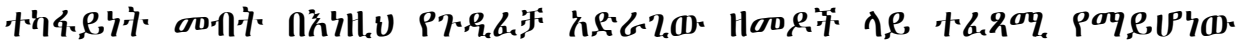

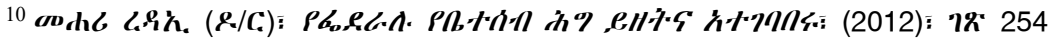

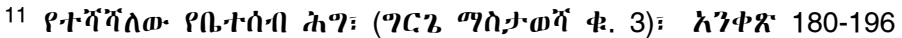

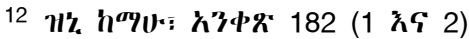

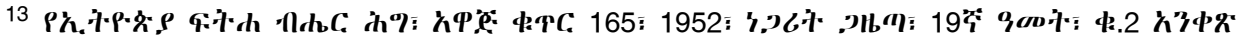
$836 / 2$

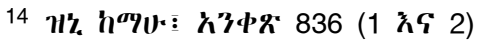




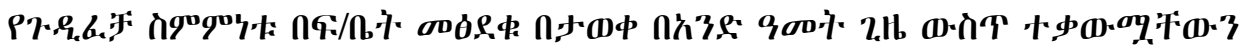

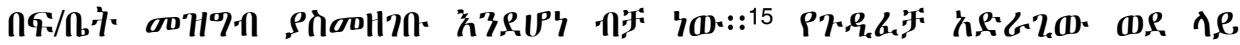

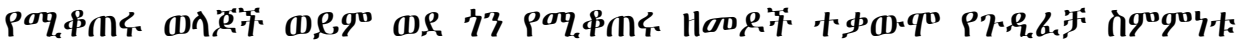

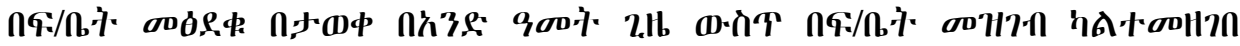

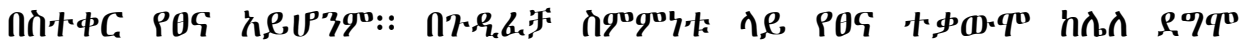

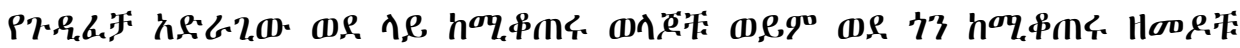

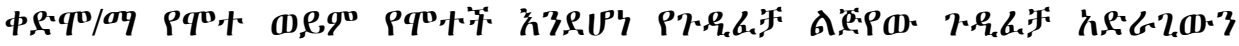

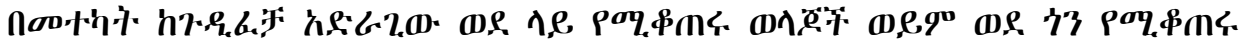

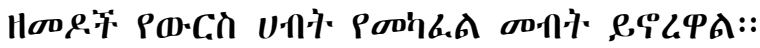

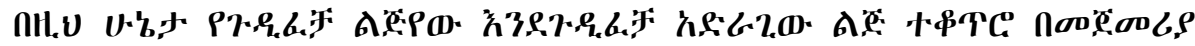

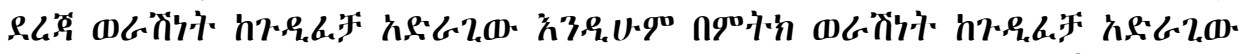

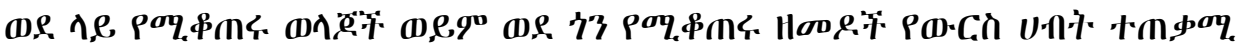

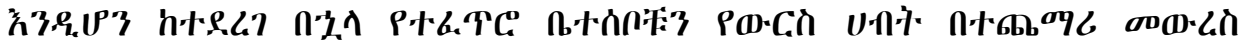

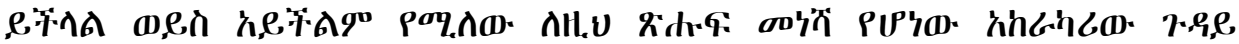

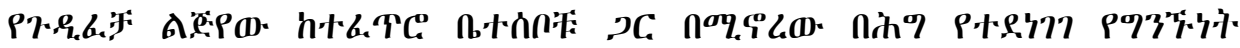

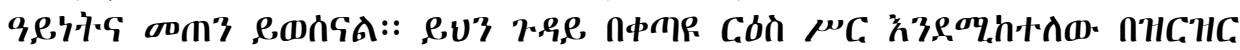

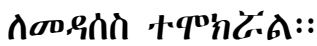

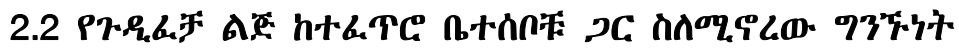

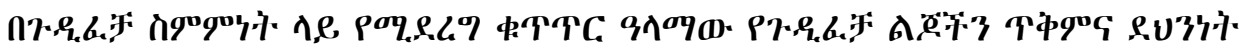

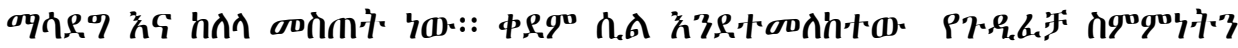

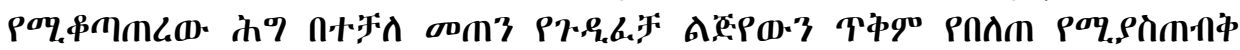
ڤ3.

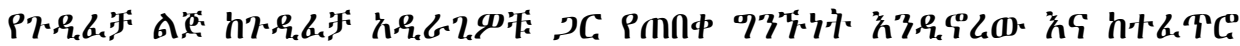

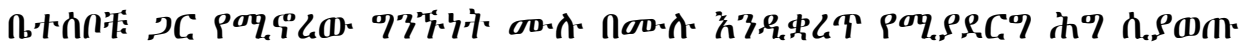

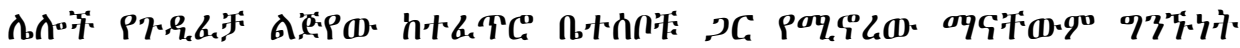

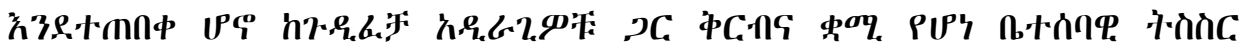

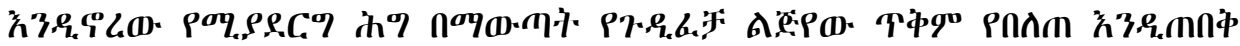

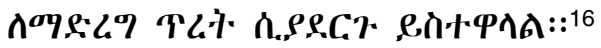

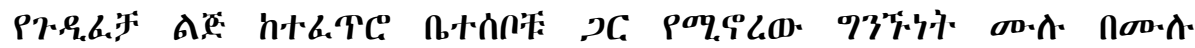

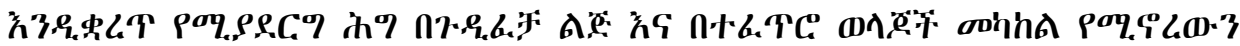

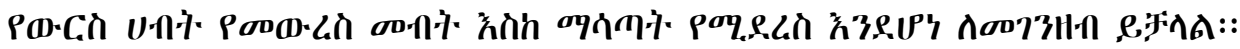

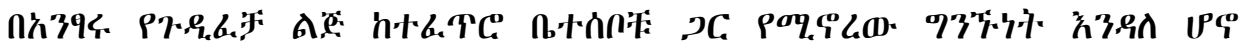

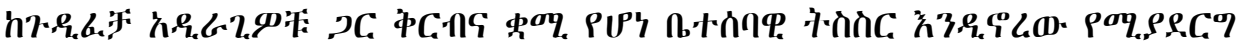

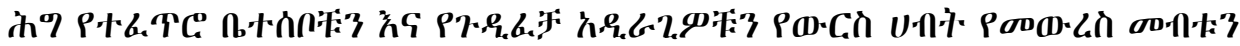

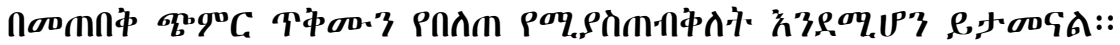

กUา6.

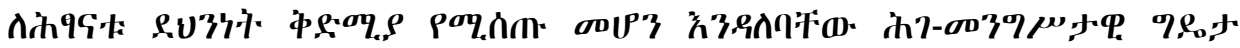

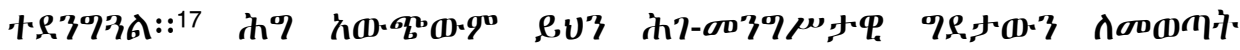

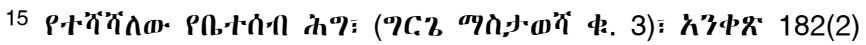

16 John R Jr Murphy, supra note 6, p. 150

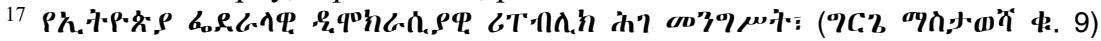




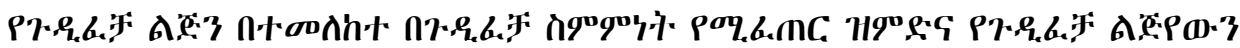

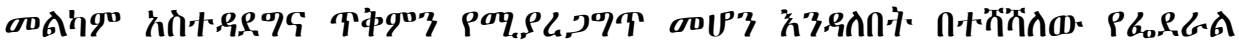

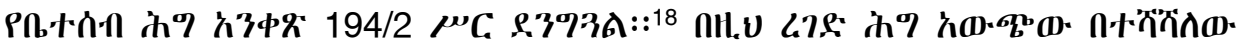

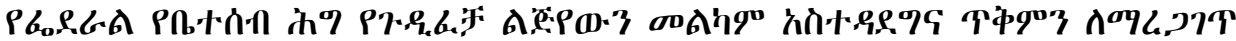

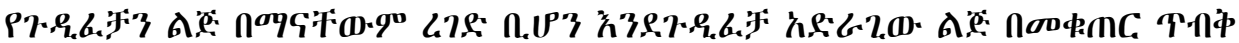

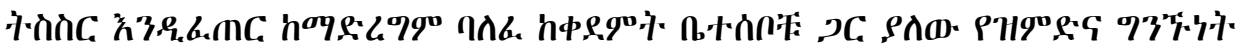

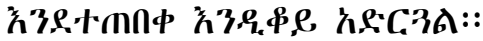

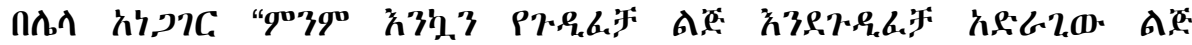

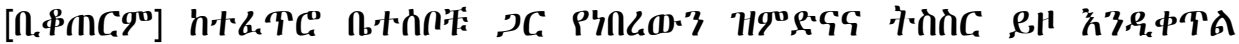

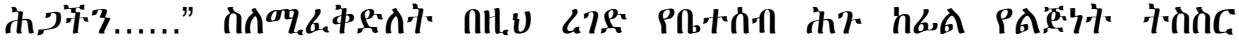

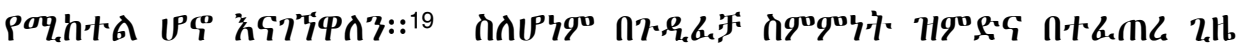

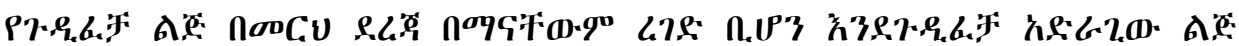

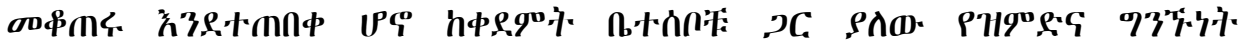
eфTAA::20

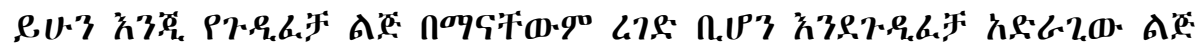

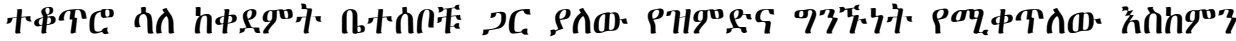

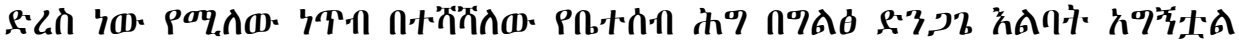
ה

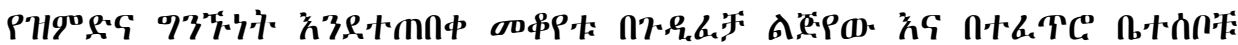

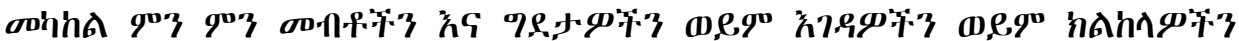

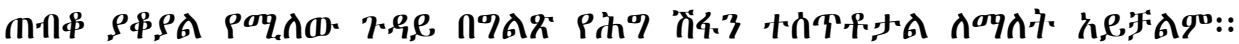
ev oqn 93 P7.

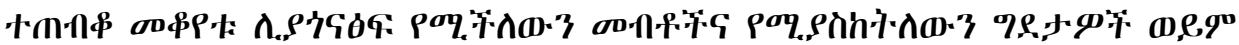

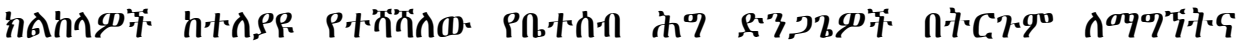

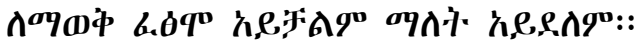

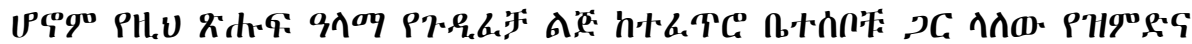

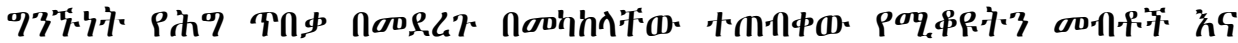

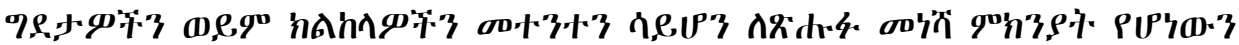

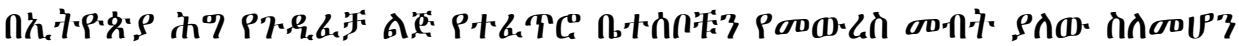

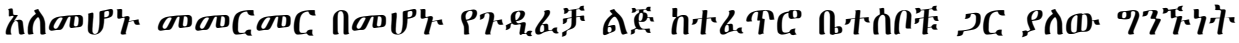

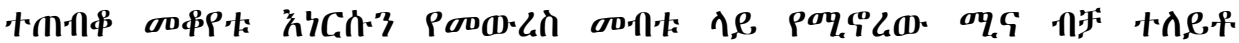

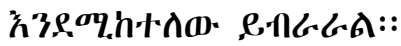

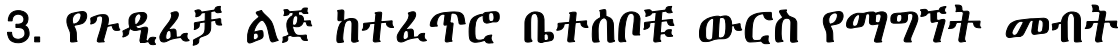

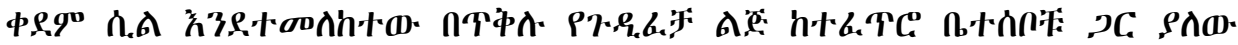

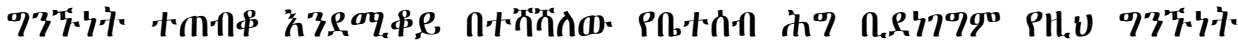

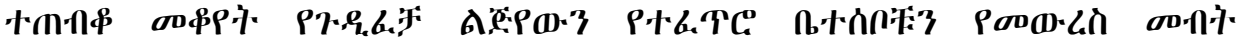

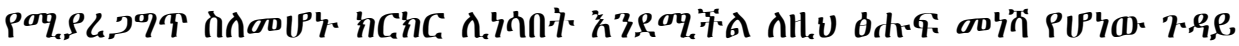

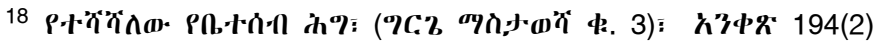

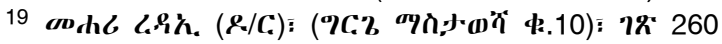

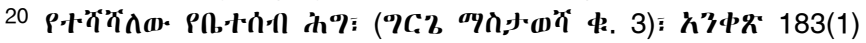




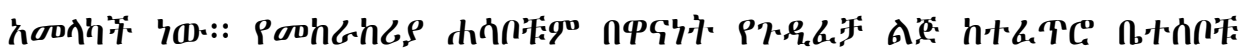
हG h7.

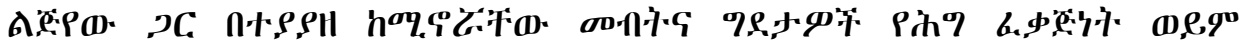

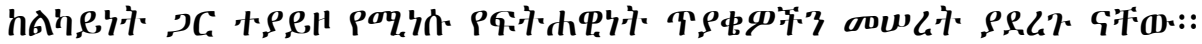

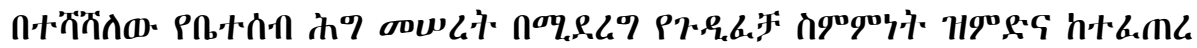

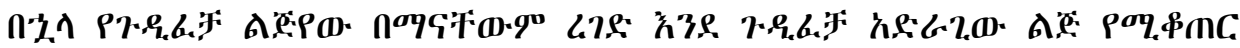

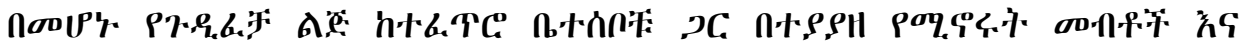

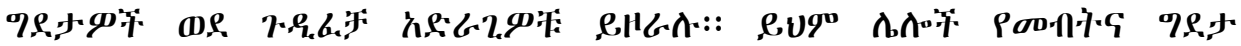
U.b., क्र कत

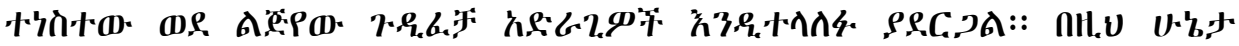

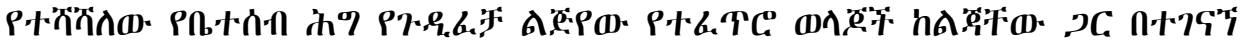

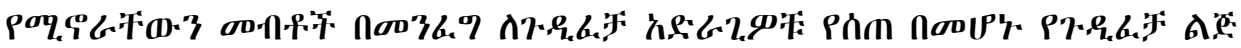

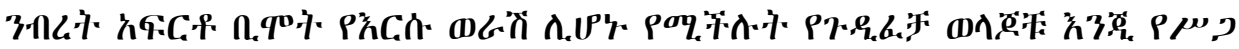

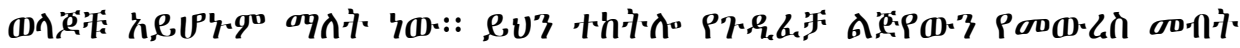

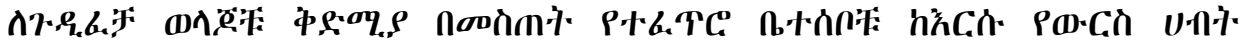

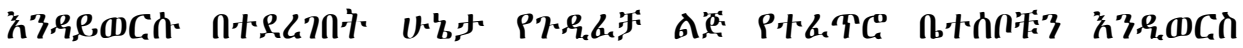

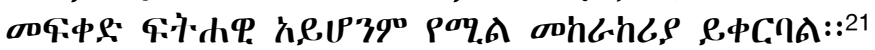

ev.

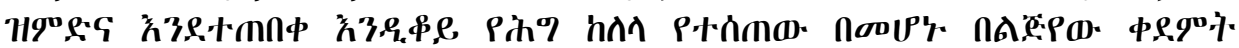

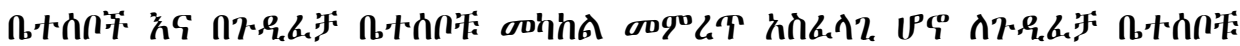

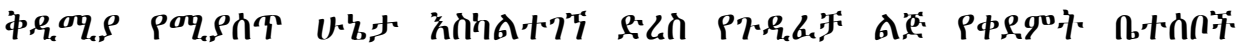

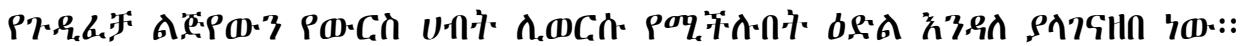

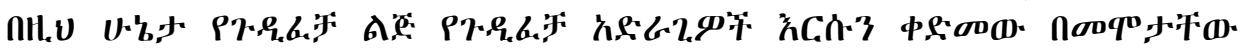

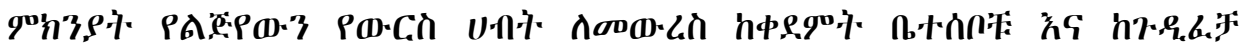

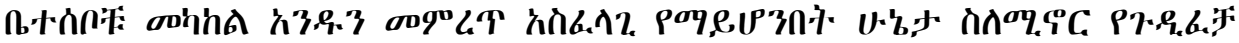

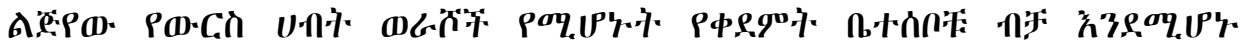

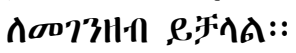

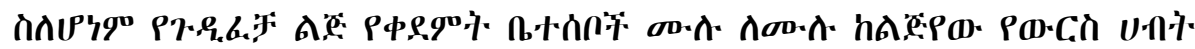

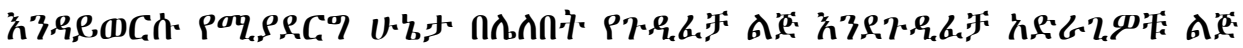

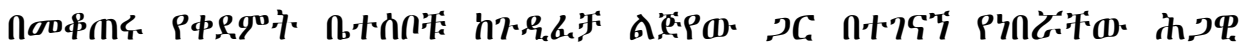

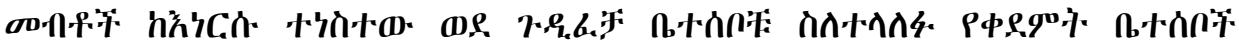

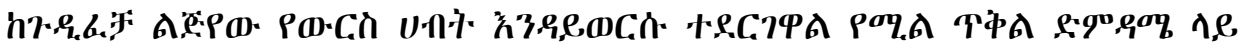

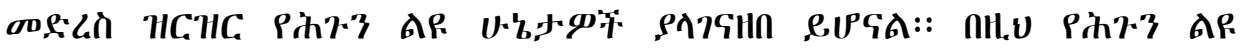

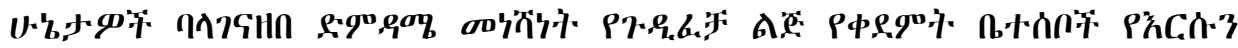

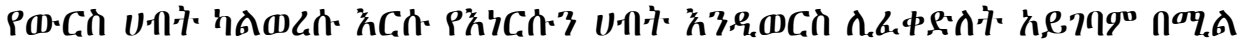

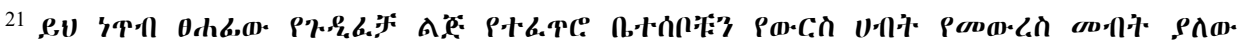
กn

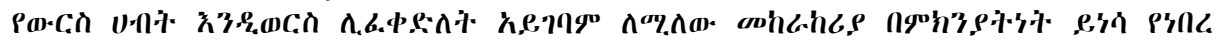
h(o): : 


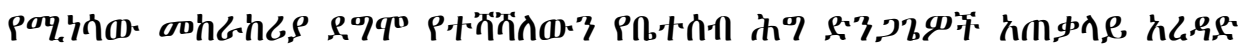

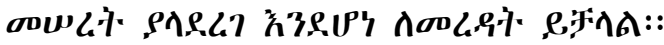

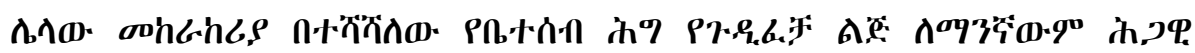

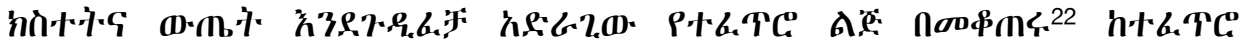

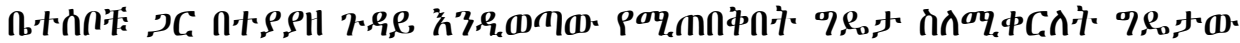

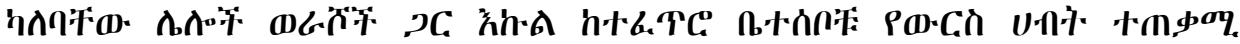

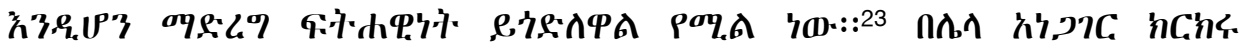

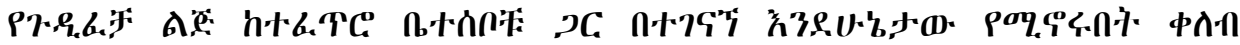

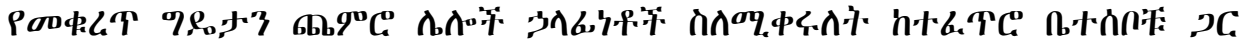

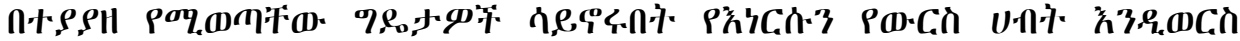

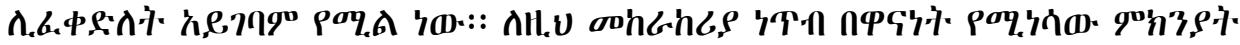

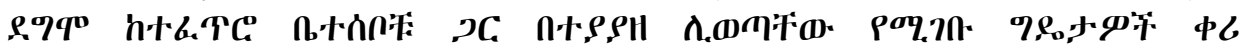
P+PL7. P7.

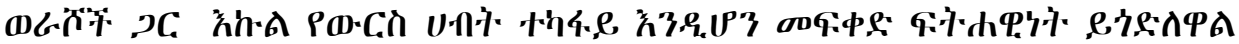
POY.A ho::

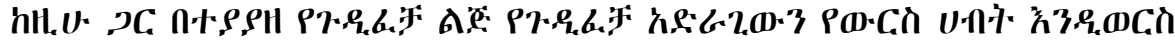

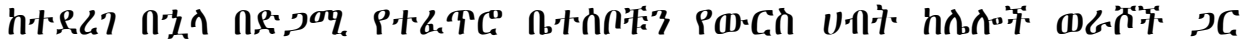

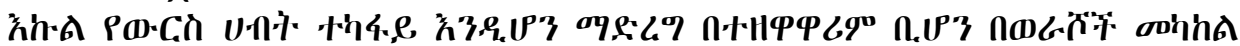

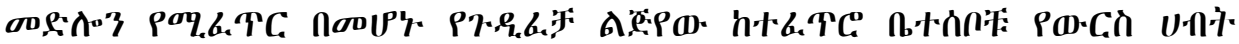

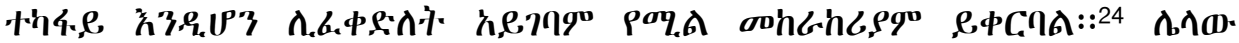

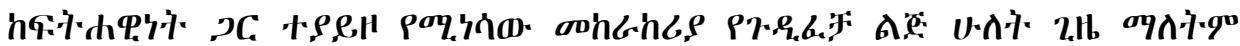
औ3

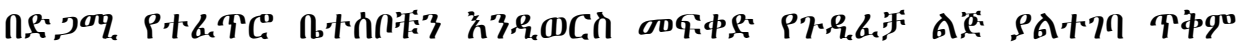
ถ

17C 93 P7.

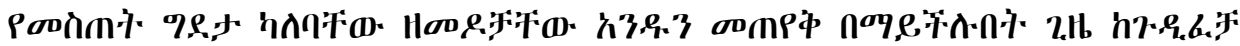

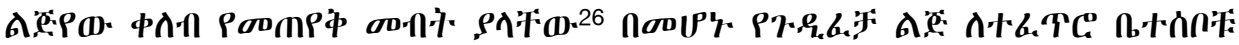

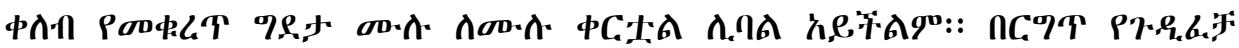
А.

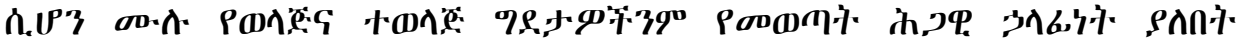

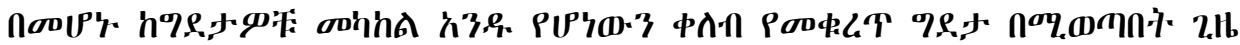

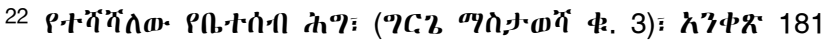

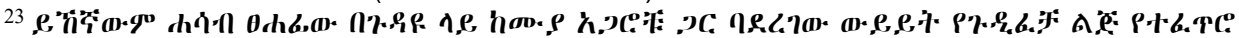

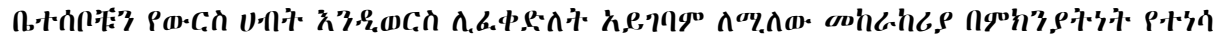
'bo': : :

24 Joel B Sherman, 'Rights and Duties of the Natural Parents of an Adopted Child' (1964-

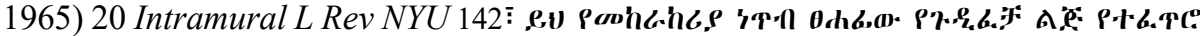

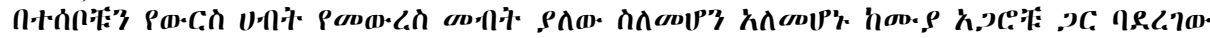

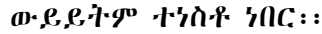

25 Charles A Taylor (1967), 'Inheritance Rights of the Adopted Child in Kentucky' 55(4) Ky LJ 874, 878

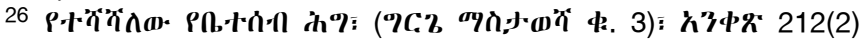




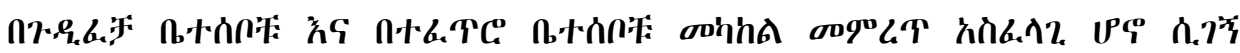

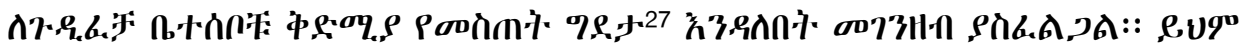

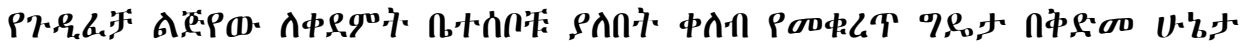

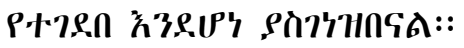

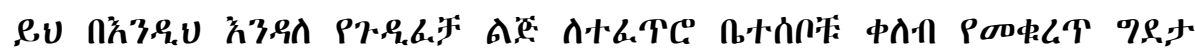

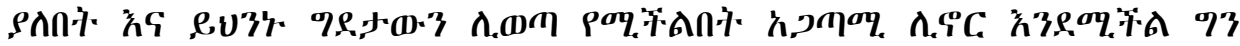

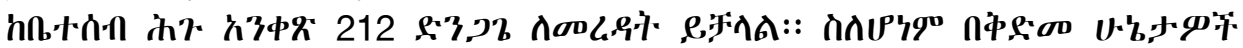

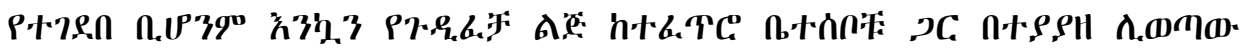

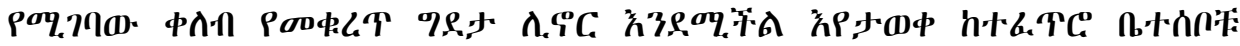

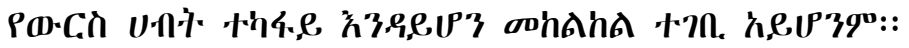

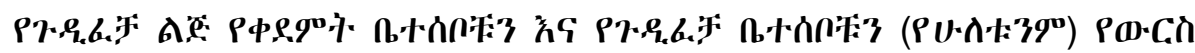

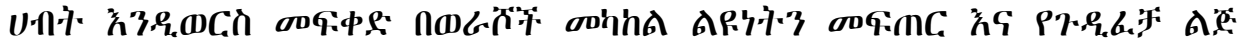

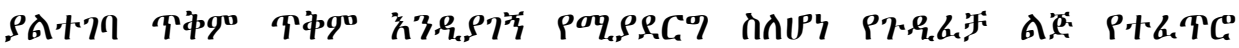

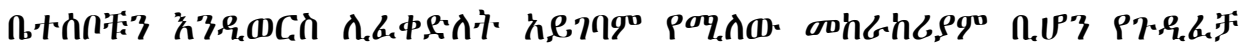

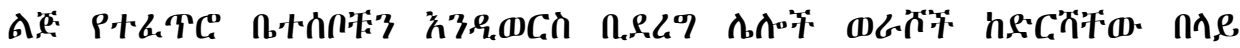

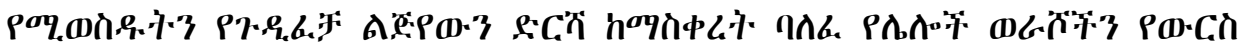

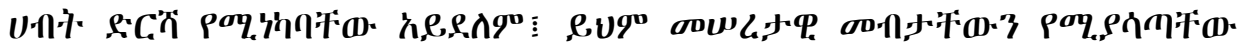

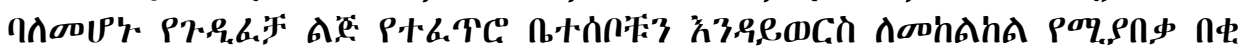

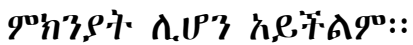

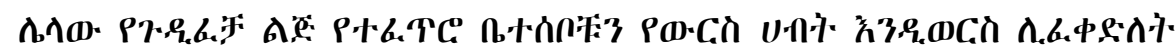
h,

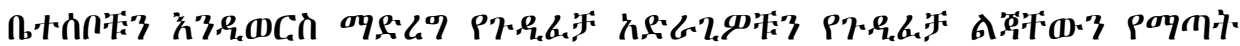

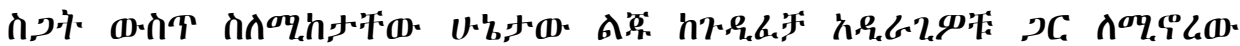

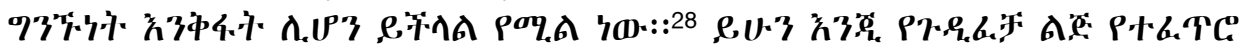

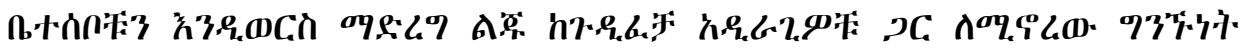

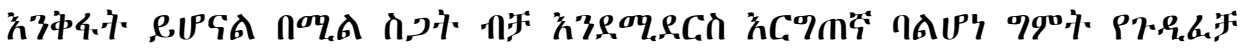

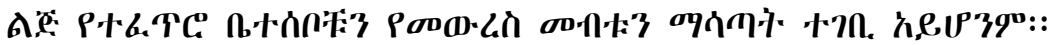

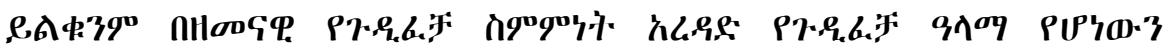

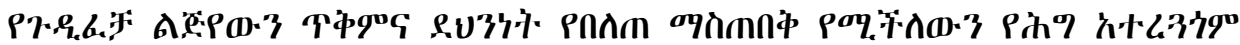

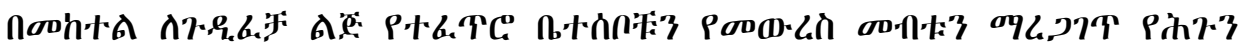

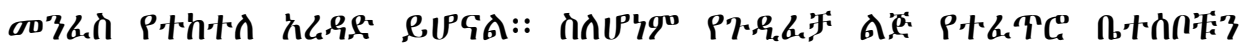

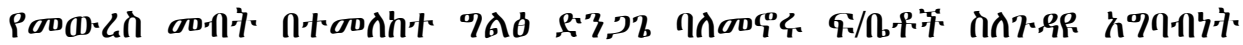

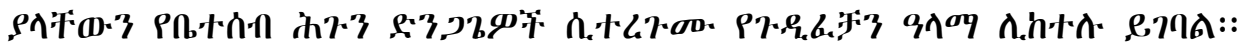

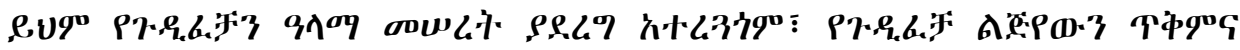
P.

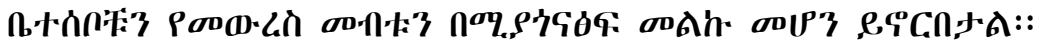

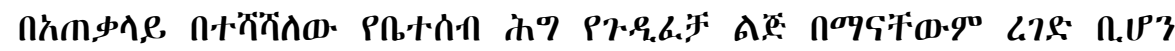

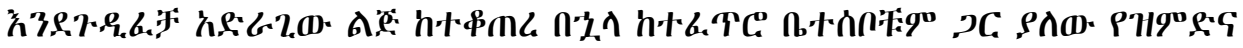

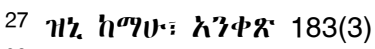

${ }^{28}$ Paul A Kiefer, supra note 1, p. 395
} 


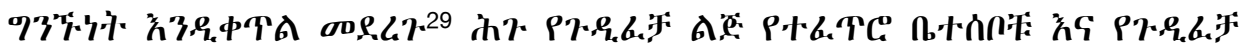

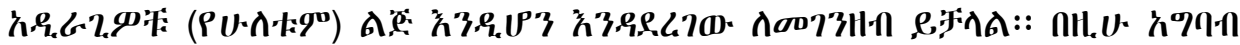

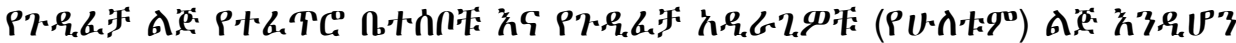

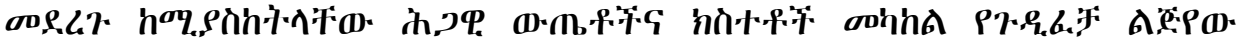

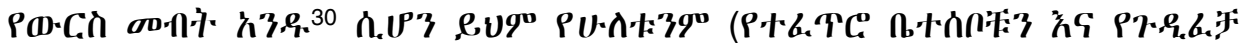

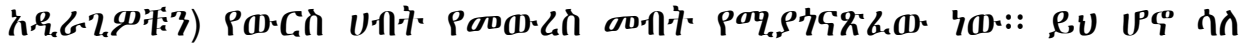

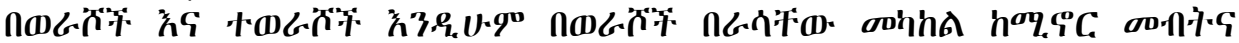
qR.

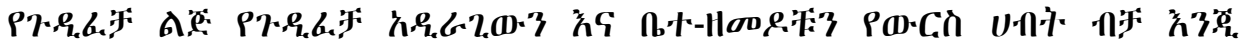

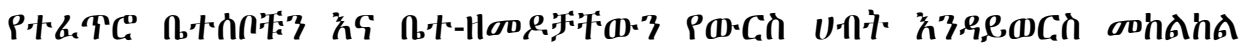

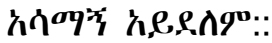

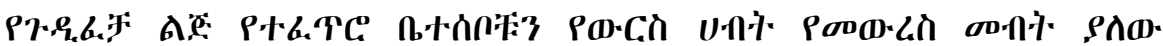

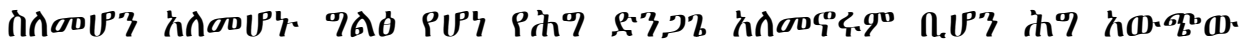

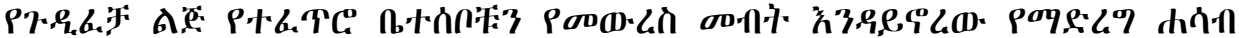

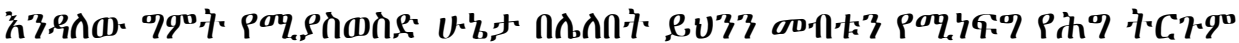

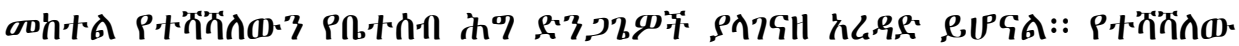

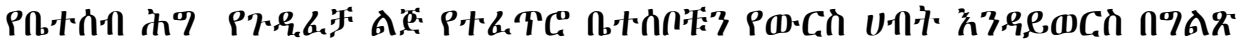

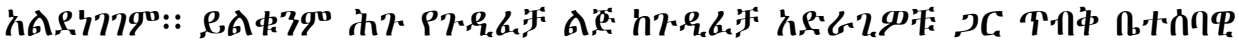

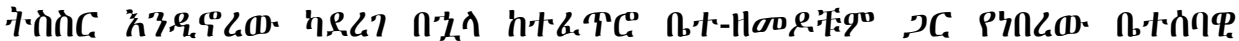

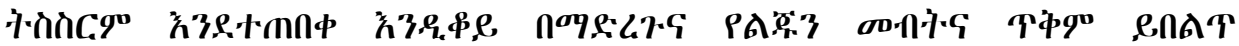
त.

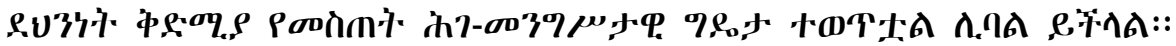

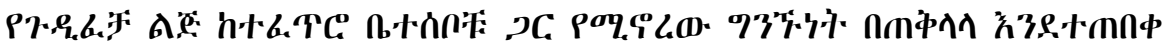

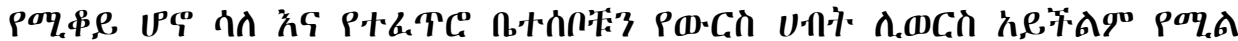

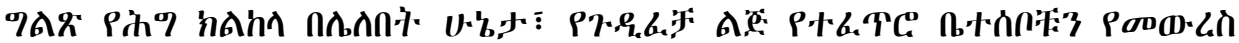

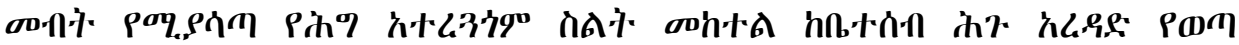

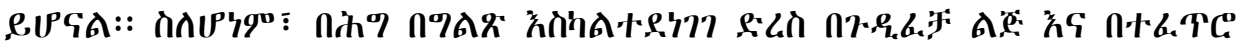

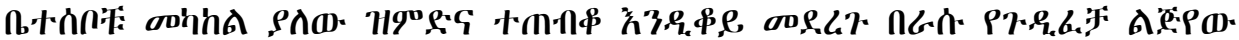

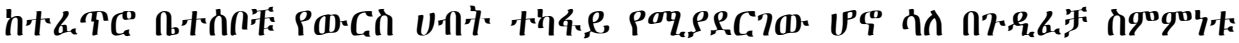

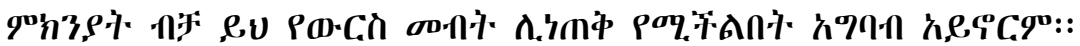

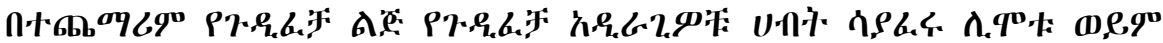

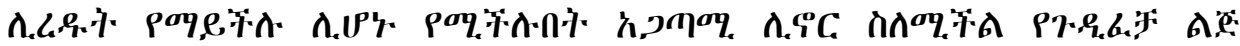

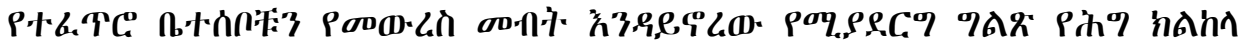

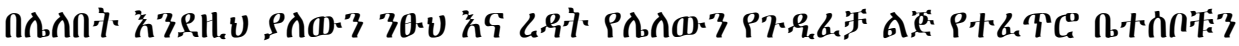

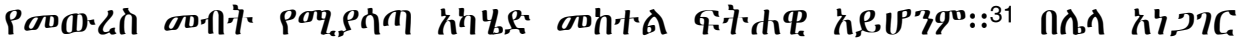

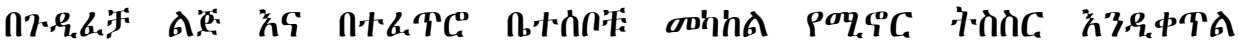

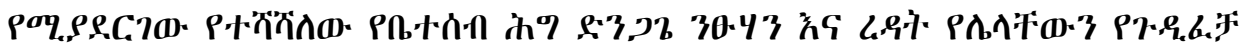

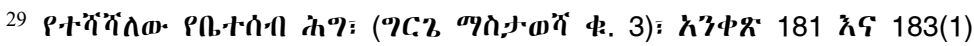

${ }^{30}$ John R Jr Murphy, supra note 6, p. 150

${ }^{31}$ Paul A Kiefer, supra note 1, p. 398
} 
А h, $\ell 799^{\circ}:$ :

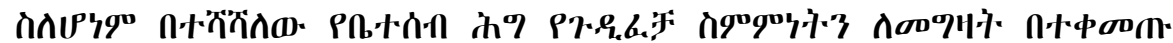

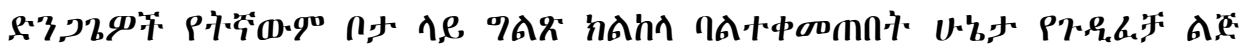

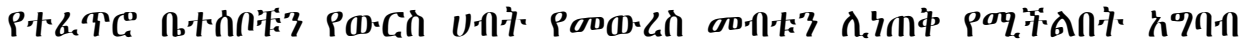

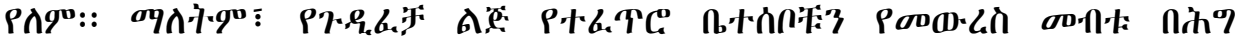

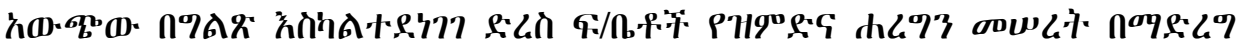

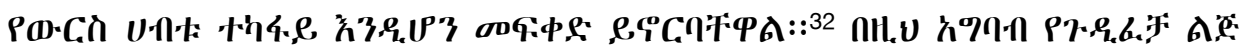

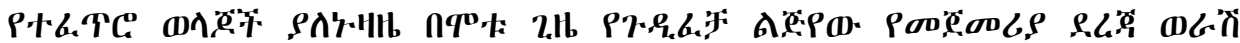

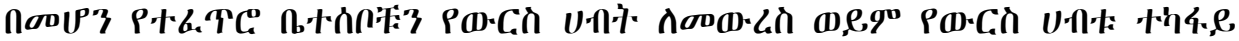

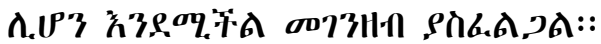

\section{4. $00 R^{\circ} Q^{\circ} q_{4} \rho$}

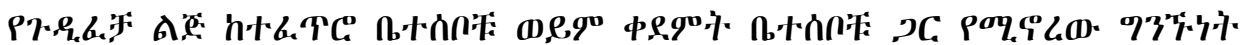

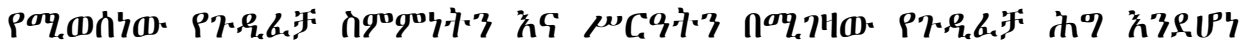

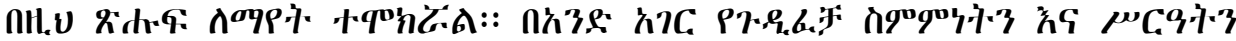

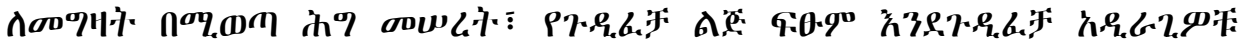

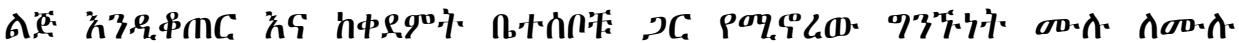

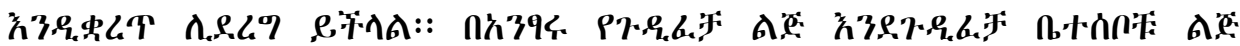

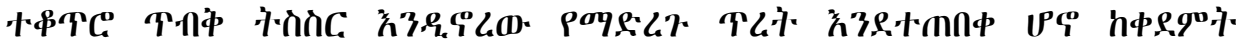

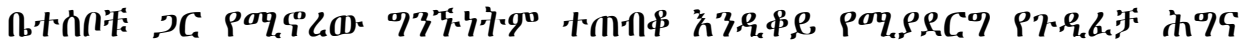

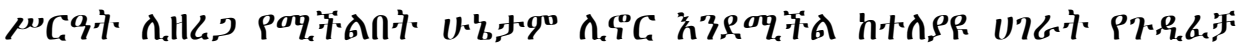

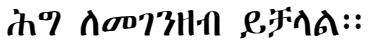

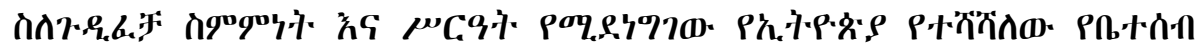

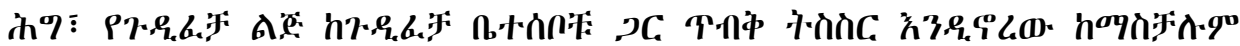

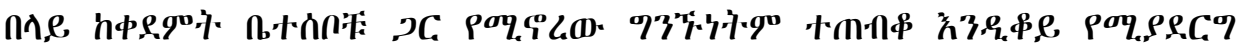

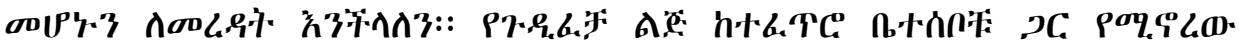

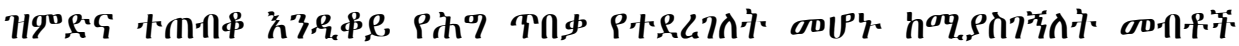

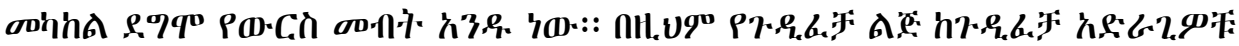

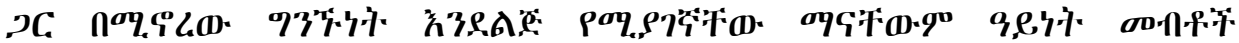

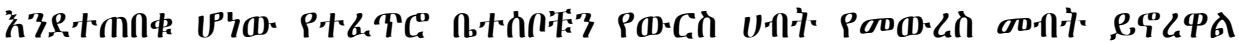

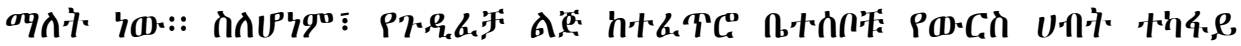

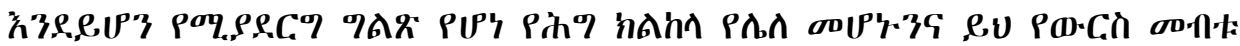

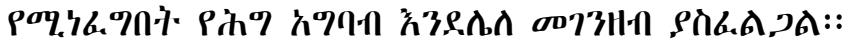

${ }^{32}$ John R Jr Murphy, supra note 6, p. 152 


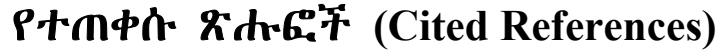

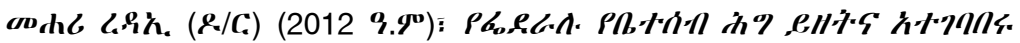

Bjertness, Donald (1957). 'Domestic Relations - Inheritance by Adopted Children - Right of Adopted Child to Inherit from Its Natural Parent' 33(2) N.D. L. Rev.

Kiefer, Paul (1966). 'Intestate Succession, Sociology and the Adopted Child', 11(2) Vill L Rev

Murphy, John (1957). 'Adopted Child's Right of Inheritance from the Natural Parents', 6 Clev-Marshall L Rev

Sherman, Joel, 'Rights and Duties of the Natural Parents of an Adopted Child' (19641965), 20 Intramural L Rev NYU

Taylor, Charles (1967). 'Inheritance Rights of the Adopted Child in Kentucky', 55(4) Ky LJ 874

Thompson, Arthur (1917). 'Right of the Adopted Child in Intestate Succession', 3(2) ABA $J 135$ 